\title{
Por un País Valenciano libre, autónomo y socialista. El PSOE y la identidad valenciana (1974-1978)
}

For a free, autonomous and socialist Valencian Country. The PSOE and the Valencian identity (1974-1978)

\author{
Vega Rodríguez-Flores Parra* \\ Universitat de València \\ vega.rodriguez@uv.es \\ ORCID: 0000-0001-8618-1583
}

Recibido: 27-2-2018

Aceptado: 23-5-2018

Cómo citar este artículo / Citation: RODRÍGUEZ-FLORES PARRA, Vega (2018). Por un País Valenciano libre, autónomo y socialista. El PSOE y la identidad valenciana (1974-1978). Pasado y Memoria. Revista de Historia Contemporánea, 17, pp. 103-125. https://doi.org/10.14198/PASADO2018.17.04

\section{Resumen}

El presente trabajo aborda la actitud del PSOE respecto a la cuestión nacional en el País Valenciano desde una perspectiva que intenta abarcar el comportamiento mostrado en relación con este asunto, tanto por estructura federal, como por las Federaciones valencianas. El periodo que engloba esta investigación se inicia con la renovación socialista de 1974, año en el que el PSOE se declaró favorable al derecho de autodeterminación y abogó por un modelo federal, y finaliza con el primer tercio de 1978, cuando el PSOE-PV presidió el Consell Preautonómic del País Valencià.

El País Valenciano ofrece una complejidad singular, ya que se trata de un lugar con peculiaridades históricas y culturales reseñables en el que el nacionalismo valencianista cobró una acusada importancia durante el periodo señalado, pero en el que la

\footnotetext{
* La autora participa en el Proyecto de Investigación: "Derechas y nación en la España Contemporánea. Culturas e identidades en conflicto" (HAR2014-53042-P), financiado por la Dirección General de Investigación Científica y Técnica, Ministerio de Economía y Competitividad.
} 
voluntad nacional e incluso la autonómica de la población fueron cuestionadas hasta que, a finales de 1977, la manifestación organizada para el Dia Nacional del País Valencià, convenció a la mayor parte del espectro político de lo contrario. En este sentido, se intenta observar cómo se encaró la cuestión identitaria desde el partido mencionado; cómo se articuló lo regional y lo nacional en su discurso; y cómo formuló su idea de nación, de España y del País Valenciano.

Palabras clave: PSOE. País Valenciano. Autonomía. Transición. Nacionalism.

\begin{abstract}
This paper addresses the attitude of the Spanish Socialist Party (PSOE) in relation to the national issue in the Valencian Country, from a perspective that tries to consider the response both of the federal structure and the Valencian Federation to the problems involved. The period covered goes from the Socialist Party renewal in 1974, when the PSOE declared itself in favor of the right to self-determination and advocated a federal model, until April 1978, when the PSOE-PV presided over the Consell Preautonomic of the Valencian Country.

The Valencian Country offers a singular complexity due to its remarkable historical and cultural peculiarities. Valencian nationalism became especially important during the above-mentioned period when the national and even autonomic will of the population was questioned. This lasted until the end of 1977, when the demonstration organized for the National Day of the Valencian Country, convinced most of the political spectrum otherwise. In this sense, the chapter analyses how the identity issue was addressed from the Party, how it articulated the regional and the national elements in its discourse, and how it formulated its idea of nation, of Spain and of the Valencian Country.
\end{abstract}

Keywords: PSOE. Valencian Country. Autonomy. Transition.Nationalism.

La cuestión nacional adquirió en la Transición española un lugar privilegiado en los debates sociales y políticos. Articular el Estado español de una manera más democrática y descentralizada se convirtió en una obsesión casi para todos los actores políticos, pero no en todos los territorios se vivió con la misma intensidad. En el País Valenciano esta cuestión levantó grandes pasiones tempranamente, pero pese a ser general el reconocimiento de su personalidad diferenciada, no todos coincidieron al señalar las implicaciones que de ello se derivaban, ni para todos resultó igual de prioritario.

Partiendo de estas premisas, en este trabajo intentaremos analizar cómo se comportó el Partido Socialista Obrero Español en el País Valenciano desde mediados de 1970 hasta la concesión de la preautonomía en el primer tercio de 1978. Cómo se enfrentó a este problema en un territorio en el que los conflictos identitarios acabarían siendo extremadamente complejos, condicionando el curso de los acontecimientos y los posicionamientos de los propios partidos. Un territorio al que difícilmente le podían ser negadas sus particulari- 
dades históricas o culturales, pero en el que fue discutida la conciencia nacional de su pueblo, uno de los motivos que de hecho explican la actitud dubitativa de gran parte de la izquierda estatal. Unas dudas que parecieron despejarse poco antes de la concesión de la preautonomía, gracias a la multitudinaria manifestación del "Dia nacional del País".

\section{La autonomía valenciana y el "programa máximo"}

Son conocidas las posiciones más maximalistas del Partido Socialista respecto al problema nacional en la España de la transición democrática. Resoluciones aparentemente rompedoras como las del XIII Congreso de Suresnes en octubre de 1974, o su sanción en el XXVII Congreso de diciembre de 1976, celebrado ya en Madrid, han suscitado animados debates sobre la veracidad y sinceridad de aquellas propuestas ${ }^{1}$.

Los socialistas enlazaron en 1974 con la defensa de un modelo federal para España, enunciada ya en 1918; y apostaron por primera vez en su historia por el derecho de autodeterminación ${ }^{2}$. Lo hacía una generación joven de socialistas que renovaban aquella organización, no sólo en la dirección sino en gran parte de las federaciones. La militancia socialista había visto interrumpida su continuidad hasta los años setenta, cuando comenzó a nutrirse de nuevos miembros que heredaban la tradición histórica de aquellas siglas pero que iban a dotar a aquella organización de un aire nuevo ${ }^{3}$.

\footnotetext{
${ }^{1}$ Durante mucho tiempo, ha sido común analizar la postura de la izquierda mayoritaria -PSOE y PCE-, desde dos perspectivas, la que incidía en que la defensa preconstitucional de los derechos de las nacionalidades oprimidas se basaba en motivaciones oportunistas y electoralistas (De Blas, 1978; Mateos, 2007; Sánchez, 2008; Quiroga, 2008; 2009); y por otro lado, la que, considerando igualmente el período del debate constitucional como el punto de inflexión en el que se modificaron los planteamientos previos, achacaba los cambios a la necesidad de establecer un consenso (Molinero, 2011). Sin embargo, una interpretación más reciente ha comenzado a inclinarse por la explicación de la evolución -marcada por las distintas coyunturas que se atravesaron durante este período- que por la de la ruptura. Así, se entiende que aunque los partidos se vieron forzados a readaptar muchas de sus estrategias y planteamientos, ello no implicaría necesariamente la transformación de sus principios (Archilés, 2009, 2015; Núñez Seixas, 2010; Rodríguez-Flores, 2017a).

2 PSOE: "Resolución sobre nacionalidades y regiones", en Resoluciones. XIII Congreso. Archivo Biblioteca Fundación Pablo Iglesias (ABFPI), Fbb 431. El federalismo había sido defendido también en 1964, aunque con escasa trascendencia, durante su IX Congreso, en el que en una declaración anexa se recuperaba la fórmula de 1918 "Confederación republicana de nacionalidades ibéricas", (Gómez Llorente, 1976).

${ }^{3}$ Fue también entonces cuando sin embargo el PSOE renovado apostó decididamente por hegemonizar el camino hacia la unidad socialista e iniciar una política de alianzas antifranquistas que sirvieran a este fin. Como consecuencia de ello, abandonó la Confederación Socialista Ibérica y reafirmó su modelo de partido federal y no de partidos federados, pese
} 
Esta actitud favorable a las demandas nacionalistas tenía, necesariamente, su traslación a las federaciones socialistas de las respectivas nacionalidades. Y así sucedió en el País Valenciano, donde desde la década de los años sesenta, y con más firmeza en los setenta, empezaron a plantearse reivindicaciones identitarias que tuvieron su correspondiente eco en las formaciones políticas, sobre todo de izquierdas, muy influidas por el fusterianismo y las corrientes intelectuales de aquella época, que partían de la premisa de que la recuperación nacional y la liberación de clase se darían de la mano, o no se darían (Archilés 2012; Rico, 2018). Así, los grupos antifranquistas fueron introduciendo progresivamente en sus programas estas demandas, haciendo que durante la Transición, conceptos como democracia y autonomía aparecieran como inseparables.

No fue ajeno a esta tendencia el Partido Socialista Obrero Español, que se encontraba a nivel de País desestructurado y con escasa militancia, hasta que la renovación tuvo lugar también en este territorio. Aunque la Federación de Alicante, la más numerosa en estos años, mantuvo una mayor continuidad, no sucedió lo mismo en Valencia y Castellón. Mientras en la última provincia el PSOE permanecería desarticulado hasta 1976, cuando comenzó a reconstruirse; en Valencia, crecería lentamente a partir de la renovación de su dirección en 1975. Entre 1975 y 1976 la Federación valenciana se fue desarrollando de manera paulatina, como resultado de un panorama socialista dividido, en el que la hegemonía no correspondía ni mucho menos al PSOE, que debía competir con el Partido Socialista Popular y el Partit Socialista del País Valencià. En cualquier caso, como en el resto de territorios, el Partido Socialista sufriría en el conjunto del País Valenciano un crecimiento acelerado en los meses previos a las elecciones, y espectacular tras estas (Sanz, 1988).

Precisamente, la competencia con otros grupos socialistas, como el PSPV, nacionalista valenciano, o en general con el conjunto de una izquierda especialmente dividida, influiría de manera decisiva en la adopción de posturas sensibles con las reivindicaciones nacionales. En este ambiente debe entenderse la carrera por integrar estas cuestiones entre los programas de los partidos antifranquistas. Sería común, por tanto, en aquellos para los que este era un problema fundamental y estaba en el origen de su razón de ser; en aquellos que podían demostrar una trayectoria de reconocimiento de estos problemas, a pesar de que no formaran parte de su médula ideológica; o incluso en

a su reciente postura favorable al Estado federal para España, (Martín Ramos, 1989). Sobre la renovación del PSOE desde el interior véase también, (De Esteban y López, 1982; Andrade, 2012). 
los que llegaban casi por imitación a su asunción, sin que en el seno de sus partidos se hubiera debatido e interiorizado de forma seria la necesidad de hacer suyas estas reivindicaciones ${ }^{4}$.

Estas actitudes se trasladaron también a las plataformas que comenzaron a surgir en el primer lustro de la década de 1970, en las que fue común la asunción de la problemática nacional en sus declaraciones programáticas. Pero aunque el conjunto de la izquierda estatal tratara de integrar estas demandas, la falta de tradición y de sensibilidad por estas cuestiones en parte de la clase política -como también entre la población-, dificultó algunos acuerdos unitarios y demostró que era en muchos casos uno de los motivos más importantes de desencuentro político. Y es que, aunque coincidieran en la voluntad unánime de demandar la autonomía valenciana, incluso dentro de este territorio, no todos otorgaban la misma prioridad a esta cuestión, y mientras para algunos era una aspecto esencial, otros creían que el proceso democrático no podía ser frenado por la manera en que se reconocía al País Valenciano este derecho, algo que como muchas otras cosas, se fue poniendo de relieve con el tiempo.

En este marco, la Junta Democrática de España presentó un programa nada maximalista ante la opinión pública el 30 de julio de 1974, basado en doce puntos que condensaban su estrategia de "ruptura democrática". En él reconocía la "personalidad política de los pueblos catalán, vasco, gallego, y de las comunidades regionales que lo decidan democráticamente", siempre "bajo la unidad del Estado español" . Este organismo, en el que el Partido Comunista de España ejercía un claro liderazgo, tuvo su correspondencia en el País Valenciano a través, primero de la creación de diferentes Juntas, como la de Alcoy o la de Valencia, y finalmente por medio de la Junta Democràtica del País Valencia ${ }^{6}$. En la Junta de Valencia, por ejemplo, la cuestión territorial fue tratada de manera tímida y dubitativa, y aunque en la declaración de la Junta del País Valenciano el 5 de agosto de 1975, se utilizó una retórica más próxima a los planteamientos valencianistas -manteniendo en todo caso la defensa

\footnotetext{
${ }^{4}$ Sobre las reivindicaciones identitarias en el País Valenciano desde el análisis de los diferentes Partidos políticos en el País Valenciano véase (Martí, 2017; Prats, 2010; Gascó, 2010; Escandell, 2014).

${ }^{5}$ Junta Democrática de España: "Declaración de la Junta Democrática de España al pueblo español". Madrid, 29-VII-1974, Archivo Histórico del Partido Comunista de España (AHPCE), Fondo nacionalidades y regiones, País Valenciano, caja 78, carpeta 9.

${ }^{6}$ Estaba formado por el Partido Socialista Popular, el Partido Comunista de España, el Partido del Trabajo de España, OCE (Bandera Roja), miembros del Partido Demócrata y Liberal del País Valenciano (PDLPV), independientes, CCOO, Justicia Democrática y Movimiento Democrático de Mujeres.
} 
de la necesaria unidad de todos los pueblos del Estado español y obviando cualquier referencia al derecho de autodeterminación-, se mantuvo implícita la idea de que debía ser la sociedad valenciana la que tenía que demandar una autonomía que las instituciones o los partidos políticos no podían imponer por la fuerza ${ }^{7}$. No estaban por tanto seguros de la existencia de una voluntad social mayoritaria a este respecto, como sí sucedía en territorios como Cataluña, Euskadi o Galicia. Afirmaban, pues, que el Estatuto tendría que ser resultado de la expresión de la voluntad soberana del pueblo valenciano, y que la autonomía no podía imponerse sin una consulta popular ${ }^{8}$.

Huelga decir que aquella indefinición de la Junta era un síntoma de la indefinición de gran parte de los partidos valencianos de "obediencia" estatal, que aunque incorporaban las reivindicaciones nacionales a sus programas, carecían de una posición meditada y firme sobre estos problemas.

Paralelamente a la organización de las Juntas, se estaba creando otro organismo unitario en competencia con las mismas, que nacía en gran medida con el objetivo de limitar la hegemonía del PCE en la política de alianzas entre la oposición. Se trataba de la Plataforma de Convergencia Democrática, impulsada precisamente por el Partido Socialista Obrero Español, Izquierda Democrática y la Unión Social Demócrata Española. En el manifiesto de la Plataforma, firmado el 11 de julio, se reconocía el derecho a la constitución de autogobiernos desde el momento de la ruptura democrática: "La Plataforma de Convergencia Democrática consciente de la existencia de nacionalidades y regiones con personalidad étnica, histórico o cultural propia en el seno del Estado español, reconoce el derecho de autodeterminación de las y la formación de órganos de autogobierno en las nacionalidades del Estado desde el momento de la ruptura democrática y propugna una estructura federal en la Constitución del Estado español"9.

${ }^{7}$ Junta Democràtica del País Valencià: Declaración de la Junta Democràtica del País Valencià. País Valencià, 5-VIII-1975, Archivo Histórico Sindical José Luis Borbolla (AHSJLB), Fondo Antonio Palomares, 13/02. Véase también Junta Democrática de Valencia: Declaración de la Junta Democrática de Valencia. AHPCE, Fondo nacionalidades y regiones, País Valenciano, Caja 77, Carpeta 2/4, p. 5.

${ }^{8}$ Según José Antonio Noguera Puchol, quien formó parte de la Junta Democràtica del País Valencià como independiente, este organismo "partía de la base de que ningún Estatuto podía ser impuesto, ni siquiera de forma provisional, ya que el País Valenciano nunca había contado con un texto jurídico estatutario en vigor que pudiera servir de referencia", (Noguera, 1977:69). José Antonio NOGUERA: Un País Valenciano autónomo en una España democrática, València, Fernando Torres Editor, 1977, p. 69. Véase también Junta Democrática de Valencia: Declaración de la Junta Democrática de Valencia. AHPCE, Fondo nacionalidades y regiones, País Valenciano, Caja 77, Carpeta 2/4, p. 5.

${ }^{9}$ Firmaron el Manifiesto, el Consejo Consultivo Vasco, Izquierda Democrática, el Movimiento Comunista de España, la Organización Revolucionaria de Trabajadores, el 
A pesar de que los partidos que habían impulsado inicialmente esta Plataforma tenían una menor tradición en su preocupación por la cuestión nacional en España, los términos de su Manifiesto asumían mejor el hecho diferencial que los de la Junta Democrática, aunque en definitiva, el reconocimiento de las libertades nacionales tuviera como fin preservar la unidad. En palabras de Santiago Míguez, la Junta se mostraba más cauta, entre otras cosas porque debía convertirse en una alternativa de poder frente al régimen, mientras que la Plataforma, al no ser una alternativa de poder, "se configuraba como un lugar de encuentro de la oposición. Su significado hay que buscarlo analizando la estrategia de sus partidos miembros y, en especial, la de socialistas y democristianos" (Míguez, 1990: 445). Una estrategia que fue considerada en algunos sectores como oportunista y ajena a las posiciones que en realidad defendían sus impulsores, entre los que destacaba el PSOE. Partido que precisamente moderaría o abandonaría sus planteamientos más radicales, no sólo respecto a esta cuestión, conforme se fue consolidando como una alternativa de poder (Gillespie, 1991; JULIÁ, 1997; Mateos, 2009; Andrade, 2012; Sabio, 2015).

Durante este tiempo, se había creado también la versión valenciana de la Plataforma entre los grupos que no querían integrarse en la Junta. Se trataba del Consell Democràtic del País Valencià, que databa del 24 de junio ${ }^{10}$, y que defendía al menos teóricamente la constitución de la Generalitat Provisional desde el momento de la ruptura, como paso previo al proceso de autodeterminación del pueblo valenciano (Sanz y Felip, 2006; Noguera, 1977).

Fruto de este contexto, los socialistas se esforzaron por mostrar una imagen amable con las reivindicaciones nacionalistas. Así sucedió en el que parece fue el primer número de Avant, el órgano de prensa de la Federación valenciana del PSOE. En coherencia con el punto quinto del Manifiesto de la Plataforma de Convergencia que habían suscrito, publicaron un editorial titulado "Federación Socialista del País Valenciano". Tanto el nombre de la publicación como el título del editorial hacían referencia a una Federación inexistente entonces ${ }^{11}$, remitiendo a un deseo de reeditar la desaparecida Federación

Partido Carlista, el Partido Gallego Social-Demócrata, Reagrupament Socialista i Democràtic de Catalunya, Unió Democràtica del País Valencià, Unión General de Trabajadores y Unión Social-Demócrata Española. Plataforma de Convergencia Democrática: "Manifiesto de la Plataforma de Convergencia Democrática", El Socialista, 44 (segunda quincena de julio de 1975).

${ }^{10}$ Formado por el PSOE, PSPV, UDPV, PCV, PSAN, MCPV, UCE, UGT y USO.

${ }^{11}$ De hecho, este órgano de prensa se definía como el "Órgano de la Federación Socialista del País Valenciano (PSOE). Comité de Valencia". Parece que se editaban al menos dos versiones, una desde la Federación de la provincia de Valencia y otra desde la alicantina. 
Socialista de Levante, sustituida en 1931 por las tres Federaciones provinciales, hechos que decían estaban siendo sometidos a una "revisión crítica de los socialistas del País Valenciano (PSOE)". Y es que una Federación para el conjunto del País Valenciano se adaptaba mejor a la defensa de la "reconquista de las libertades de las regiones y nacionalidades ibéricas" por la que abogaban. En un número que además publicaba íntegra la "Resolución sobre nacionalidades y regiones" del Congreso de Suresnes, se decantaban de manera coherente con las nuevas directrices por una "República Federal de las Nacionalidades, de modo que se quebrante la estructura de un Estado que ha sido modelado en forma adecuada para convertirlo en instrumento de opresión y explotación por las clases dominantes". Así pues, se trataba de una postura que buscaba ante todo contribuir a la lucha de clases, sin olvidar a los "trabajadores inmigrados" ni por supuesto al resto de los territorios españoles, con los que aquella ficticia, todavía, Federación Socialista del País Valenciano, debía coordinarse para combatir al enemigo de la clase trabajadora, que por supuesto no conocía de fronteras ${ }^{12}$. Nada nuevo por tanto, ya que se trataba de legitimar la lucha nacional, como había hecho a nivel estatal el PSOE, a partir de los derechos de los pueblos oprimidos, pero sobre todo, a partir de su utilidad como una parte más de la lucha de clases. Por ello, el derecho de autodeterminación que propugnaban los socialistas no podía entenderse sin comprender que para ellos era enunciado a partir de la convicción de que otorgarlo fortalecería la unidad nacional española, ya que de otra manera, la clase trabajadora estaría supeditando los intereses nacionales a los de clase, algo que el Partido no podía consentir.

\section{Adaptar el proceso autonómico a la "conciencia nacional"}

Es evidente que a principios de los años setenta el PSOE - sin cuestionar el marco nacional español ni la unidad del Estado- hacía esfuerzos por comprender la complejidad nacional española, integrándola en su discurso. Esto conllevaba una serie de dificultades que se hicieron más patentes en unos territorios que en otros. Y a la hora de definirse, no fue sencillo para los socialistas hacerlo en relación al País Valenciano, un lugar donde las reivindicaciones nacionales desde el ámbito político pero también desde el social , aunque existían, no eran unánimes ni contaban con una trayectoria consolidada.

A pesar de ello, el País Valenciano aparecía como la unidad de referencia que construir, y la reivindicación de sus derechos nacionales se convertía en

${ }^{12}$ Avant, julio-agosto de 1975. 
un objetivo cada vez más prioritario para la oposición democrática. Así sucedería por tanto en la Taula de Forces Polítiques i Sindicals del País Valencià, constituida el 19 de mayo de 1976. Nacía de la confluencia del Consell Democràtic del País Valencià y la Junta Democràtica del País Valencià, tal y como había sucedido a nivel estatal el 26 de marzo con la fusión entre la Junta y la Plataforma, dando lugar a Coordinación Democrática. El programa de la Taula reclamaba la autonomía política para este territorio, lo que suponía una aspiración común de las fuerzas democráticas valencianas. Pero, además, en su punto quinto, enunciaba que con el proceso constituyente se crearía de forma inmediata la "Generalitat provisional del País Valencià"13. Esta cuestión estaba envuelta en la recurrente polémica sobre si se debía imponer la autonomía, o no, desde el mismo momento de la ruptura. El problema radicaba en el término "Generalitat Provisional", porque, como ya indicó José Antonio Noguera Puchol -quien también formó parte de este organismo hasta octubre de 1976-, la Taula no explicó jamás que entendía por esta fórmula, quizá porque no hubo nunca consenso para ello (Noguera, 1977: 71). Jesús Sanz ha apuntado, por otra parte, que "Generalitat provisional" sería una fórmula intermedia entre la elegida por el Consell "Gobierno provisional autónomo" y la que prefería la Junta, "órganos de poder provisional suficientes", y que quedaba abierta a diversas interpretaciones: la del Gobierno provisional de la Generalitat, que equiparaba al País Valenciano con las tres nacionalidades históricas; o la de la "Generalitat como forma de autogobierno", que "entendía ese «Gobierno provisional», como un resultado al que el País Valenciano llegaría durante el proceso constituyente para toda España" (Sanz, 1982: 28-29).

Esta ambigüedad sería visible en las reuniones internas de la Taula, en las que no existiría unanimidad a la hora de establecer qué significaba el punto quinto de su declaración. Aunque era general la preocupación de los representantes valencianos por que se reconociera la personalidad de este País y la autonomía de la Taula en una posible integración en una plataforma superestructural, no todos tenían clara la estrategia, ni desde luego en todos los casos este tema ocupaba un lugar prioritario ${ }^{14}$. En este sentido, los socialistas igual que los comunistas, llamaban la atención sobre la conveniencia de no ir más allá del acuerdo tomado por la Taula a este respecto, en el que en todo caso,

\footnotetext{
${ }^{13}$ Taula de Forces Polítiques i Sindicals del País Valencià: "Acord Constitui de la Taula de Forces Polítiques i Sindicals del País Valencià”. 19-V-1979, Archivo Personal de Víctor Fuentes Prosper (APVFP).

${ }^{14}$ Conocemos el contenido de estas reuniones gracias las notas personales de uno de sus participantes, Víctor Fuentes Prosper, como representante de la Federación del País Valenciano del PSP, las cuáles son auténticas actas de aquellos encuentros.
} 
como recordaban, todavía no había una posición definida y unánime sobre la autonomía ${ }^{15}$.

Estas discusiones se situaban en un contexto en el que se estaban llevando a cabo reuniones entre Coordinación Democrática y el resto de instancias de la oposición en las regiones (l'Assemblea de Catalunya, la Taula, la Táboa Democrática de Galicia, etc.), para llegar a una integración en la Plataforma de Organismos Democráticos (Míguez, 1990). Pero el reconocimiento de las demandas valencianas encontró importantes obstáculos, como indica el testimonio de Noguera Puchol:

El reconocimiento de nuestra voluntad de constitución de una "Generalitat Autónoma desde el momento de la ruptura" originó múltiples conflictos a la hora de engarzarlo con las aspiraciones de otras organizaciones unitarias del Estado. Al parecer, el País Valenciano debía resignarse a ser comprendido como una nacionalidad de segundo orden, que, a falta de antecedentes históricos, no podía plantear su autonomía más que después y a lo largo del propio proceso constituyente del Estado. La estrategia de la Taula desde su iniciación estuvo dirigida, con algún éxito inicial y posiblemente un cierto fracaso final, a conseguir romper tal planteamiento (Noguera, 1977:71-72).

En cualquier caso, los partidos de "obediencia estatal" integraron las demandas autonómicas en sus programas. En aquellos momentos parecía que no se podía ser de izquierdas sin defender los derechos de las nacionalidades oprimidas, y en el País Valenciano este era un tema que comenzaba a demostrar un importante respaldo popular, como indicó por ejemplo, la manifestación del 12 de julio de 1976, en la que, según los datos ofrecidos por los organizadores, entre 120.000 y 150.000 personas salieron a la calle al grito de Llibertat, Amnistia i Estatut d'Autonomia! ${ }^{16}$. Los partidos estatales comenzaron cada vez más a organizarse en torno a esta estructura territorial, añadiendo al final de sus siglas las del PV, tanto por motivos estratégicos como ideológicos. De este modo, el PSOE, iría conformando progresivamente una nueva estructura organizativa, aunque de manera lenta en comparación con otros partidos. Pese a que no se convirtió en una Federación única en el País Valenciano hasta 1978, desde mediados de 1976 se creó un Comité de enlace para facilitar la coordinación entre las tres federaciones de Valencia, Alicante y Castellón.

Pero pese a que los socialistas se vieran embarcados en una política que contaba entre uno de sus objetivos el de "fer País", ya en aquellos momentos

${ }^{15}$ Véase, por ejemplo, FUENTES, Víctor: Notas reunión Taula de Forces Polítiques i Sindicals del País Valencià, 10-VI-1976, APVFP.

${ }^{16}$ Avui, 18 de julio de 1976; Las Provincias, 5 de agosto de 1976. 
existían en la práctica límites que no tenían intención de sobrepasar. Así, contradicciones que se harían muy evidentes conforme la coyuntura política obligaba a jerarquizar intereses y prioridades, sobre todo a partir de 1979, existían ya en aquella época. Por ejemplo, mientras defendían por un lado un teórico derecho a la autodeterminación como nacionalidad oprimida, por otro ponían en duda el grado de conciencia nacional del pueblo valenciano. Así se pronunciaba a finales de 1976 uno de los miembros de la Comisión Ejecutiva de la Federación valenciana del PSOE y futuro Presidente del Consell Preautonòmic del País Valencià, José Luis Albiñana:

És una dada sociològica el fet que el poble valencià no té un grau elevat de consciència nacional com el tenen Euskadi, Catalunya i Galícia. La major sensibilització correspon, d'altra banda, als sectors més conscienciats políticament, que assumiran o no, als seus programes, la necessitat de l'alliberament nacional sota les fórmules de simple descentralització o d'autonomia. Nosaltres defensem l'Autonomia del País Valencià, ja que creiem que, en qualsevol dels casos, el País Valencià té dret a l'autodeterminació (Fabregat, 1977:159-160).

No se puede desvincular este planteamiento de las reservas que tanto socialistas como comunistas mantenían en el organismo unitario valenciano acerca de la igualación en derechos con las tres nacionalidades históricas. Como hemos referido, ambos partidos estatales mantendrían evidentes reticencias en los momentos decisivos sobre otorgar un Gobierno provisional desde el momento de la ruptura. La ambigüedad en el discurso se observaba en múltiples ocasiones, como sucedía en la anterior entrevista concedida por Albiñana, que se ralizó en medio de la polémica que vivió la Taula por la negativa de la oposición democrática estatal a reconocer explícitamente su punto quinto del programa. La Plataforma de Organismos Democráticos sólo mencionó el restablecimiento provisional de las instituciones autonómicas de los "casos más específicos de Catalunya, Euskadi y Galicia"17. Y Albiñana, pese a reconocer al País Valenciano como una nacionalidad oprimida a la que le correspondía el derecho de autodeterminación y a la Taula como la institución a través de la cual reclamarlo, abogaba también por un referéndum que después, y no antes, de la conquista de la democracia, permitiera al pueblo demandar, que no votar, un Estatuto de Autonomía (Fabregat, 1977:152-153 y 161).

Lo cierto es que el Partido Socialista, a nivel estatal, pero también en el País Valenciano, no priorizaba en la práctica, al menos con urgencia, la defensa de unos derechos que en todo caso querrían aplazar para que no interfirieran

${ }^{17}$ Plataforma de Organismo Democráticos: "Programa político de la Plataforma de Organismos Democráticos". Madrid, 23-X-1976, APVFP. 
negativamente en el curso de la negociación democrática entre las fuerzas de la oposición y el Gobierno, por considerarlos -en el mejor de los casos- secundarios. La Taula -en la que estaban integrados partidos nacionalistas que sí presionaban por la consecución de los derechos nacionales valencianos- en la medida en la que se empeñaba en seguir posicionándose públicamente por una estrategia menos conciliadora con una deriva que estaba marginando al País Valenciano, comenzó a suponer un estorbo para el PSOE. Algo que se evidenció en una de las crisis que esta institución sufrió durante aquellos meses, y que acabó con la salida de la misma del grupo socialista. El conflicto estalló cuando fracasaron definitivamente los esfuerzos de la Taula por conseguir un representante en la Comisión que debía negociar con el Gobierno ${ }^{18}$. La POD decidió el 1 de diciembre que esta se compondría de diez miembros, entre los que tres de ellos fueron nombrados por las tres nacionalidades históricas, en teórica representación del conjunto de los territorios que conformaban el Estado español.

Ante esta situación, la Taula emitió un comunicado de rechazo a las decisiones adoptadas por la POD, que se iniciaba de la siguiente manera: "La Taula, en les actuals circumstàncies, no ratifica l'acord subscrit. La Taula entén que el P.V ha estat marginat d'una participació directa en les negociacions, la qual cosa no se correspon amb el nivell de lluita i de consciència popular expressats pels valencians reiteradament" 19 .

El texto no pretendía, sin embargo, distanciar esta instancia unitaria de la POD, pero sí apelar a una reconsideración de las circunstancias por parte de la misma. Y a pesar de esto, el Partido socialista, el Partido comunista y CCOO votaron en contra (mientras que UGT y el PSP se abstuvieron) ${ }^{20}$. Este fue el detonante para la salida de los socialistas del País Valenciano de la Taula -aunque asistiría a partir de entonces en calidad de invitado a las reuniones-. Los socialistas emitieron un comunicado en el que, ellos sí, ratificaban el documento suscrito el 1 de diciembre en Madrid; y en el que, aunque decían lamentar

${ }^{18}$ Las explicaciones que se dieron ante la Taula, como expondría Manuel Broseta en la prensa, fueron que debía cortarse en el País Valenciano "el aluvión" de territorios que reclamarían un puesto en la Comisión, empezando por Canarias, Andalucía, Aragón o Baleares. Broseta, además, dejaba que claro que ninguno "de los llamados grandes partidos, desde la derecha hasta la izquierda, del Estado Español", aludiendo sin duda al PSOE y al PCE, había apoyado la petición de la Taula, Manuel BROSETA: "La marginación del País Valenciano", Las Provincias, 19 de diciembre de 1976. Sobre el socialismo y la autonomía en Andalucía y Aragón, véanse respectivamente (RUIZ, 2005; SABIO, 2017).

${ }^{19}$ FUENTES, Víctor: Notas de la reunión de la Taula de Forces Polítiques i Sindicals del País Valencià. València, II-XII-1976, APVFP.

${ }^{20}$ Las Provincias, 23-XII-1976. 
la no inclusión del País Valenciano en la Comisión Negociadora, quitaban hierro al asunto, explicando que se trataba sólo de una cuestión formal, ya que en la práctica este estaría representado por los partidos políticos de ámbito estatal, como el PSOE, que asumían en sus programas la defensa de todos los pueblos del Estado español, y en concreto, en este territorio, abogaban por el Estatuto de Autonomía. Por todo ello, concluían reprobando la actividad de la Taula y cuestionando sus motivaciones: "La Federación Socialista del PV (PSOE), aunque considera válidos los compromisos asumidos en la declaración constitutiva de la Taula, entiende que esta no representa hoy, las aspiraciones reales de libertad y democracia del País Valenciano, suspendiendo temporalmente la asistencia a sus plenarios"21.

Con el tiempo, con la Comisión de los nueve (pasó de diez a nueve al renunciar la Coordinadora de Organizaciones Sindicales a nombrar su representante $)^{22}$, las plataformas unitarias perdieron gran parte de su vigencia, pero pese a todo, en el País Valenciano siguió viva cierta polémica al respecto, que incomodaba de manera notoria a los socialistas, partido al que se acusaba de "sucursalista" y que había dado argumentos a sus detractores con este tipo de actuaciones. Por ello, como se desprende de las declaraciones de Joan Lerma meses después (cuando formaba parte de la dirección colegiada de la Federación valenciana del PSOE), intentaban desprestigiar la función de la Taula, pero sobre todo, la de los movimientos políticos que en su seno -y en feroz competencia con el PSOE por el potencial electorado, como sucedía con el PSPV- mantenían posiciones más maximalistas en relación a la cuestión autonómica, que en su opinión ponían en peligro objetivos más elevados y necesarios, como el de la consecución de la democracia:

Se nos ha acusado a nosotros de que abandonábamos los Organismos unitarios, pero nadie ha dicho que hay partidos que siguen la farsa de hacer creer que están negociando con el Gobierno, cuando permaneciendo allí, en realidad están defendiendo intereses de partido que en nada benefician a la clase trabajadora porque conducen a la confusión (...). Desde esta perspectiva creo que se entiende mejor nuestra posición en la Taula. Nosotros no estamos allí para imponer nuestro proyecto político, sino para ayudar a que venga la democracia. Si la Taula hace ya algún tiempo que atraviesa una crisis, habrá que buscar los responsables entre estas actitudes y las de aquellos que pretenden

${ }^{21}$ Las Provincias, 4-XII-1976.

${ }^{22}$ Estaba formada por Felipe González (PSOE); Enrique Tierno Galván (PSP); Simón Sánchez Montero (PCE); Francisco Fernández Ordóñez (socialdemócratas); Joaquín Satrústegui (liberales); Antón Canyellas (democristianos); Jordi Pujol (Cataluña); Julio Jáuregui (País Vasco); y Valentín Paz Andrade (Galicia). 
que la Taula asuma posiciones muy respetables, pero alejadas de la conciencia actual del pueblo del País Valenciano ${ }^{23}$.

\section{Construir el Partido Socialista del País Valenciano}

Tras el nombramiento de la Comisión Negociadora, otros sucesos decisivos marcaron el rumbo de la nueva etapa, en la que el peso de la política unitaria se rebajó considerablemente. Entre la abrumadora victoria del sí en el Referéndum sobre el Proyecto de Ley para la Reforma Política del 15 de diciembre; y la inminencia de la convocatoria de las elecciones de 1977, los partidos políticos se centraron preferentemente en sus propias dinámicas, y comenzaron a mirar hacia el futuro en clave electoral.

En este contexto, las tres Federaciones socialistas en el País Valenciano, se dispondrían a celebrar, tras el XXVII Congreso del PSOE en diciembre de 1976, sus respectivos congresos -denominados como Asambleas Provinciales-, entre enero y febrero de $1977^{24}$. En la Asamblea Provincial de Valencia, celebrada entre el 12 y el 13 de febrero, se decidió organizar, de acuerdo con las Federaciones de Castellón y Alicante, el I Congreso del Partido en el País Valenciano, que oficialmente uniría en una, las tres Federaciones valencianas. Así se relataba en el órgano de prensa del Partido en Valencia, que adaptaba la estructura en el País a la situación política del momento y a las directrices que, planteadas desde el Congreso de 1974, se habían visto confirmadas en 1976: "En lo que respecta a la estructura federal, no es extraño que pretendamos, en estos momentos, consolidar una organización (...) respondiendo a las premisas fundamentales de estos tiempos: la Federación de nacionalidad o región". Pero tal declaración iba acompañada por una doble justificación, habitual en sus discursos. Por un lado trataba de conectar tal medida con una larga trayectoria histórica, que había comenzado con su defensa del Estado Federal en 1918, desmintiendo por tanto que se debiera a una actitud oportunista. Por otro, seguramente pensando en aquellos que no veían la necesidad de plegarse a los intereses nacionales y que entendían el internacionalismo de una manera estrecha, como incompatible con la defensa de los derechos de las nacionalidades, argumentaban que la lucha de la clase trabajadora necesitaba adquirir la conciencia nacional, pero no a partir "concepciones burguesas"

${ }^{23}$ Avant, 3, 10-IV-1977. En realidad, los socialistas sí estaban negociando directamente con el Gobierno, mientras que la Taula tenía poca influencia en este sentido, debido a la mencionada pérdida de relevancia de aquellos organismos y a la no representación de esta en la Comisión de los nueve.

${ }^{24}$ La Asamblea de la Federación de Castellón tuvo lugar el 9 d enero y la de Alicante el 16 de enero. 
que implicaran la necesidad de obtener un Estado, sino para reforzar la lucha de clases, por lo que entendían, que esta nueva organización debía estar coordinada necesariamente de forma federal, "por cuanto entendemos que la lucha por el socialismo no se limita, única y exclusivamente a responder miméticamente en los lugares más concienciados nacionalmente, sino en todo el Estado Español. Por eso estamos, entre otras cosas, por un Estado Socialista de estructura Federal, y no por una Federación de Partidos"25.

Las nuevas ejecutivas salientes de las Asambleas fueron las que se encargaron de organizar las primeras elecciones democráticas tras la Dictadura, en junio de 1977. Todos los partidos que se presentaron a las elecciones en el País Valenciano hicieron de la autonomía un punto importante de su campaña, también el PSOE. Pero como en toda España, las diferencias entre el "programa máximo" y "mínimo" de los socialistas se hicieron aún más visibles, y las declaraciones más radicales no estuvieron presentes en su campaña. No hubo, por tanto, promesas electorales que fueran más allá del autogobierno, algo que en todo caso se planteaba como irrenunciable.

Por ejemplo, ante un cuestionario que el diario Las Provincias realizó a las diversas fuerzas políticas, el Partido Socialista Obrero Español en el País Valenciano, se proclamaba como defensor de la "unidad del Estado Español", unidad que sin embargo no podía "basarse, como hasta ahora en la fuerza, sino que ha de articularse mediante una fórmula constitucional libremente aceptada y abierta entre las distintas nacionalidades y regiones, como a la flexibilidad necesaria para su progresivo desarrollo y concreción. (...) Los Diputados socialistas del pueblo valenciano junto con los demás del partido defenderán el Estatuto de Autonomía para el País Valenciano y lo conseguirán"26.

En este momento, además, se agravó la competencia con otros grupos socialistas, y en concreto, con el PSPV. Este, plenamente identificado con las sensibilidades nacionalistas en el País Valenciano, era el partido que había conseguido aglutinar y representar la tradición del socialismo valencianista durante el postfranquismo y la Transición, lo que suponía una clara alternativa al Partido Socialista en el País Valenciano, que aparecía desde este prisma como un partido de "obediencia estatal". Ya hemos visto cómo los socialistas valencianos trataban de justificar sus posiciones, intentando ligar los nuevos planteamientos a una tradición anterior que habría sido cortada de manera abrupta por el Franquismo, pero evidenciando que la lucha nacional debía quedar supeditada a la consecución de la democracia y de los derechos e intereses de

\footnotetext{
${ }_{25}$ Avant, III Época, 1, 29-II-1977.

${ }^{26}$ Las Provincias, 9-II-1977.
} 
la clase trabajadora de todo el Estado. Así, frente a las acusaciones de "sucursalismo", el PSOE se defendía en ocasiones afirmando su implicación como socialistas en la defensa de los derechos de las nacionalidades oprimidas y como garantes de los derechos de la clase obrera de cada nacionalidad; y otras, a partir de la descalificación de su adversario, afirmando que el nacionalismo era una cuestión burguesa que colisionaba con los intereses del socialismo, como haría el propio Albiñana pocos meses después de aquellos comicios: "Las tensiones nacionalistas las ha traído siempre la burguesía. Históricamente así es, y el socialismo y el nacionalismo son dos objetivos que han aparecido separados" ${ }^{\prime 2}$.

Pero de cualquier modo, el mensaje cuajó en el País Valenciano, donde la victoria del PSOE fue inesperada pero rotunda ${ }^{28}$, obteniendo 13 escaños frente a los 11 de UCD y los 2 del PCPV ${ }^{29}$. Por otra parte, su triunfo frente al resto del socialismo valenciano les situó en una posición privilegiada para liderar una integración en condiciones de desigualdad para el resto. Posiblemente, a esta victoria contribuyó la división que sufrió el PSPV poco tiempo antes de los comicios y en la que, para muchos protagonistas, tuvo una influencia directa el PSOE (Arnal, 2005). Además, gran parte de los autores que han trabajado esta cuestión han planteado que el PSOE estaba llevando a cabo una estrategia de neutralización y absorción del resto del socialismo a partir de la división de la Federación de Partidos Socialistas, y para ello, minar las fuerzas del PSPV se desvelaba como fundamental en el País Valenciano. Parece que de haber sido así tuvieron éxito, ya que la división previa y la confusión que se generó en torno a las siglas permitió que la coalición electoral formada por el Partido Socialista Popular y la escisión del PSPV, Unitat Socialista del País Valencià, no obtuviera más que un escaño, mientras que el otro sector del PSPV, ahora en la coalición PSPV-Bloc, se quedó sin representación parlamentaria.

De esta manera, los resultados electorales demostraron que la sociedad del País, en la práctica, había penalizado a los partidos de obediencia exclusivamente valenciana y se había premiado a los estatales, que habían desplazado a este territorio a una segunda línea en la reivindicación autonómica, a pesar

\footnotetext{
${ }^{27}$ Las Provincias, 31-VIII-1977.

${ }^{28}$ Poco antes, el recién elegido miembro de la Secretaría general de la Federación valenciana Manuel del Hierro junto a Joan Lerma y Joan Pastor, afirmaba que esperaban obtener 5 diputados, aunque quitando importancia al resultado, ya que veían tan improbable una victoria que aseguraban que en realidad su objetivo al presentarse a aquellas elecciones era "tener ocasión de empezar a difundir al máximo nuestro programa", Avant, III Época, 1, 29-II-1977.

${ }_{29}$ Véase http://www.juntaelectoralcentral.es/cs/jec/documentos/GENERALES_1977_ Resultados.pdf
} 
de que todos ellos habían apoyado el autogobierno en su campaña. Pero un autogobierno que no pretendía igualarse, al menos de entrada, al que obtendrían las tres nacionalidades históricas. Y la clave en este sentido se encontraba en la convicción de los socialistas de que el apoyo popular no era tan amplio y por tanto, aunque las instituciones y los partidos políticos tuvieran la obligación moral de extender la conciencia identitaria entre la sociedad y "fer País", la autonomía no se podía imponer desde arriba, ya que, como Lerma señalaba: "debe ser una decisión a tomar por todo el pueblo valenciano, sin protagonismos falsos ni dirigismos de ningún tipo si queremos llamarnos demócratas". Como ya habían hecho anteriormente, se defendían de las acusaciones de centralismo o sucursalismo apelando a una concepción del País Valenciano basada en la voluntariedad, y afirmando de manera implícita en este caso la inexistencia de pruebas sobre la presencia de una mayoría social en favor de una autonomía que permitiera a la clase política asumirla sin más ${ }^{30}$. Más explícita sería otra afirmación de Lerma realizada poco después, cuando explicaba que en España existían tres nacionalidades históricas que habían demostrado su deseo a autogobernarse durante la II República, pero que en el País Valenciano faltaba "ese elemento de voluntariedad que el pueblo (...) habrá de demostrar"31.

La oportunidad de demostrarlo llegó poco después, el 9 de octubre de aquel año, que supuso la confirmación de que la sociedad valenciana clamaba con fuerza por la autonomía. La manifestación del que se había convertido en el día nacional del País Valenciano fue la más multitudinaria de la historia en este territorio -en la época se habló de la asistencia de unas 500.000 personas-. Se trataba del plebiscito que necesitaba aquella izquierda de "obediencia estatal", de la legitimación que requerían para enfrentarse a una negociación con los poderes del Estado ${ }^{32}$. En la rueda de prensa que ofrecieron los parlamentarios valencianos al término de la manifestación, se aseguró que aquel día se había demostrado que la conciencia del País había sufrido un "salto cualitativo" desde las elecciones del 15 de junio y que se había producido una transformación de la realidad que les situaba en una nueva posición desde la que exigir unos derechos que ya nadie podría negarles. En palabras del representante socialista: "Si en las Cortes todavía no se comprende, si muchos

\footnotetext{
${ }^{30}$ LERMA, Joan: “¿Qué supone la Autonomía para la Federación Socialista del País Valenciano?, Avant, III Época, 1, 29-II-1977.

${ }^{31}$ Avant, 3, 10-IV-1977.

${ }^{32}$ Un impacto muy similar produjo aquella conmemoración en el PCPV (RODRÍGUEZFLORES, 2017b).
} 
creen que el País Valenciano es una nacionalidad de segundo orden, tendrán que reconocer su equivocación"33.

Este análisis sería confirmado por postreros exámenes del propio Partido socialista sobre aquella etapa. En el editorial de su congreso de febrero de 1978, relataban:

Hemos tenido que soportar críticas mal-intencionadas. Hemos visto, día tras día, como se acumulaban sobre nosotros acusaciones de centralismo. Pero la posible preocupación que estos ataques pudieran causarnos desapareció cuando el pueblo valenciano tuvo la oportunidad de hablar. Los miles de Castellonenses, Alicantinos y Valencianos, la mayoría de los ciudadanos del País valenciano, dijeron un SI rotundo a la alternativa socialista que representaba nuestro partido destrozando, con la fuerza de la realidad, los débiles argumentos de aquellos que habían hecho del PSOE el blanco de sus ataques. (...)

Así, el partido "centralista" se ha convertido en la pieza clave para la consecución de ésa preautonomía que, con todas sus limitaciones, (...), va a permitir que el pueblo valenciano recupere parte de su soberanía, sentando las bases para la consecución, una vez aprobada la constitución, de la Autonomía con mayúsculas que ese pueblo pedía cuando votaba al PSOE y cuando el 9 de octubre salía a la calle afirmando su personalidad en forma sorprendente para propios y extraños ${ }^{34}$.

Pero lo cierto era que, como ellos mismos ratificarían en otros informes internos, no habría sido hasta aquel día en el que el pueblo valenciano expresó con rotundidad su voluntad de autonomía cuando los socialistas apostaron por reconocer aquel derecho autonómico de manera inmediata, sin esperar a que se preguntara oficialmente a través de un referéndum si aquella sociedad quería o no el autogobierno, asumiendo que el País Valenciano ya había hablado: "La táctica del Partido en esta materia, tanto antes del 15 de junio de 1977, como entre esta fecha y el 9 de octubre, estaba bien alejada de defender el régimen preautonómico. En este terreno había una gran coincidencia con UCD". Y añadían páginas después: "Fue la impresionante multitud de manifestantes que recorrieron las calles de Valencia la tarde del día 9 de octubre último, (...), la que definitivamente orientó la táctica del PSOE hacia la obtención de la preautonomía" 35 .

En este contexto tuvo lugar el I Congreso del Partido Socialista Obrero Español en el País Valenciano (PSOE-PV). Celebrado entre el 25 y el 26 de

\footnotetext{
${ }^{33}$ Cal Dir, 29, 16-10-1977.

${ }^{34}$ PSOE-PV: I Congreso del PSOE al País Valencià. Alacant, 25/26-II-1978, AFPI, fc 74.

35 "Partido, autonomía y Consell". Arxiu Històric de la Universitat de València (AHUV), Fons Alfons Cucó, 20/01, pp. 1-3.
} 
febrero de 1978. Este congreso sería el encargado de unir en una sola Federación, las tres Federaciones provinciales que hasta ahora existían en el País Valenciano. En él se sancionó una política más favorable a los derechos autonómicos, acorde a los cambios que se estaban produciendo tras el punto de inflexión que había supuesto el 9 d'octubre y animados también por las perspectivas de unidad con el resto del socialismo valenciano, especialmente con el nacionalista PSPV $^{36}$. Y así podía observarse en el slogan que habían elegido para su primer congreso: "Per l'autonomia al socialisme".

En su Resolución Política, se definían como un partido identificado -como consecuencia de su carácter democrático- con la "personalidad nacional del País Valencià, lo que le impulsa a avanzar en la lucha por el socialismo y la libertad de nuestro pueblo", pero siempre en solidaridad "con todos los pueblos en lucha por sus libertades nacionales y de clase". No se observaban novedades reseñables a este respecto: apoyaban la lucha nacional como una parte más de la lucha de clases y del avance de la democracia, y siempre, por tanto, en acuerdo con el conjunto del Estado y con el PSOE, ya que entendían que "la inserción de nuestra organización en el seno del PSOE es la mejor forma de expresar nuestra solidaridad con todos los trabajadores de los pueblos que forman España"37. El aspecto que contenía mayor novedad era quizá el que atendía a la preautonomía, a la que se consideraba como positiva, pese a sus "limitaciones y deficiencias", ya que ofrecía la posibilidad de conseguir la autonomía inmediatamente después de que la Constitución fuera aprobada, y porque permitía afianzar la personalidad y la confianza del pueblo valenciano ${ }^{38}$.

Una preautonomía que fue concedida por el Gobierno de Suárez a través de un decreto-ley el 17 de marzo de 1978 y que dio lugar a la creación del Consell Preautonòmic del País Valencià, presentado formalmente el día 16 de abril de 1978, bajo la presidencia de los socialistas -representados por José Luis Albiñana-. Se comprometía a dotar al País Valenciano de la plena autonomía,

${ }^{36}$ La coalición electoral Unitat Socialista del País Valencià, y el Partido Socialista dieron a conocer su acuerdo de unidad a principios de año. Los militantes de esta coalición participaron incluso en la redacción de las ponencias sobre organización y línea política. $\mathrm{Y}$ aunque el proceso no fue tan sencillo con el PSPV, las negociaciones ya estaban abiertas en aquellos momentos, de modo que las influencias en las resoluciones del congreso en relación a la posición del PSOE-PV sobre el problema nacional fueron notables. En todo caso, estas fueron mayores a partir de su integración efectiva el 25 de junio de 1978, cuando tuvo lugar el Acto Protocolario de Unidad, en el que el Partido pasó a denominarse PSPV-PSOE (aunque no se produciría este cambio oficial hasta el siguiente congreso en febrero de 1980).

${ }^{37}$ PSOE-PV: "Resolución política", en I Congreso del PSOE al País Valencià..., p. 1.

${ }^{38}$ Ibid., pp. 7-8. 
y para ello contaba con el apoyo de todas las fuerzas parlamentarias valencianas, como se demostró con el Compromís autonòmic, firmado el 8 de octubre de 1978.

\section{El espejismo del consenso autonómico}

La ilusión de consenso que la manifestación de la Diada había generado a finales de 1977, supuso un chispazo que despejó muchas dudas y convenció a casi todos de la conveniencia de que sus partidos asumieran y lideraran aquel movimiento en pro de una autonomía que igualara al País Valenciano con las llamadas nacionalidades históricas y que devolviera a este territorio unos derechos como comunidad que históricamente les habían sido negados. Los socialistas, que nunca habían discutido la existencia de una personalidad propia en el País Valenciano, ni los beneficios que la descentralización y un posible futuro autogobierno supondrían para esta sociedad, dieron un paso más a finales de 1977, considerando que la conciencia identitaria del pueblo valenciano había sido probada y asumieron estas demandas con una fuerza renovada.

No puede decirse que los socialistas se "apuntaran" de manera oportunista a defender unos planteamientos que nunca les habían representado. Es cierto, como ellos mismos se encargaban de repetir, a modo de justificación, que existía una tradición de reconocimiento de estas cuestiones -aunque vaga e interrumpida-, y que a principios de la década de 1970, la renovación en el Partido había tenido muy en cuenta estos problemas. Y aunque existiera una motivación electoralista común a cualquier otra formación, este no era ni mucho menos el único factor que les movía. Pero estos problemas estuvieron planteados desde posiciones que en el fondo siempre habían jerarquizado otros principios, entre ellos el de la unidad del Estado y de la nación. El 9 d'octubre había supuesto un punto de inflexión, que si bien no alteraría en exceso las prioridades socialistas, sí reforzaría la voluntad autonomista del partido.

El PSOE-PV decidiría entre finales de 1977 y principios de 1978 avanzar de manera decidida hacia el autogobierno, intentando situarse a la cabeza de aquellas demandas. No hay que olvidar que en junio de 1978 culminaría el proceso de integración del socialismo valencianista, que no haría sino reforzar este carácter. Pero poco duraría este impulso. El consenso pronto comenzó a desaparecer en la sociedad valenciana, y los problemas identitarios alcanzaron una virulencia extraordinaria y poco común en otros territorios, dando lugar a la llamada Batalla de Valencia, en la que la cuestión de los símbolos fue instrumentalizada por el anticatalanismo (Flor, 2011; Ribera, 2017). La situación comenzó a tornarse poco a poco en excepcional, y la coyuntura política pondría a los socialistas en el brete de tener que jerarquizar y priorizar 
planteamientos que el consenso, cuyo mayor exponente se había vivido en octubre de 1977, había permitido compatibilizar (Rodríguez-Flores, 2014). Un conflicto que erosionaría su convicción autonomista -o al menos los medios a través de los cuales se llegaba al autogobierno- conforme abría grietas en la convicción autonómica del pueblo valenciano; y cuya magnitud y alcance seguramente no se había previsto desde el socialismo, cuando a finales de 1977 la voluntad popular había sido expresada de forma unívoca. Entonces, el PSOE-PV lo tuvo claro, cualquier reticencia o duda había quedado despejada, la defensa de la máxima autonomía posible parecía la única opción. Los hechos posteriores desmintieron aquella previsión.

\section{Bibliografía}

ANDRADE, Juan Antonio (2012). El PCE y el PSOE en (la) transición. La evolución ideológica de la izquierda durante el proceso de cambio político. Madrid: Siglo XXI.

ARCHILÉS, Ferran (2009). El "olvido" de España. Izquierda y nacionalismo español en la Transición democrática: el caso del PCE, Historia del Presente, 14, 103-122.

ARCHILÉS, Ferran (2012): Una singularitat amarga. Joan Fuster i el relat de la identitat valenciana. Catarroja: Afers.

ARCHILÉS, Ferran (2015). Nacionalismos y culturas políticas en España (C. 19752012). En PÉREZ LEDESMA, Manuel; SAZ, Ismael (coords.). Del Franquismo a la democracia, 1936-2013, (141-174). Madrid: Marcial Pons.

ARNAL, Rafa (2005). Uns països sense política. En MOLLÀ Toni et al. Nosaltres exvalencians (138-167). Barcelona: La esfera de los libros.

DE BLAS, Andrés (1978). El problema nacional-regional español en los programas del PSOE y PCE. Revista de Estudios Políticos, 4, 155-170.

DE ESTEBAN, Jorge; LÓPEZ GUERRA, Luis (1982). Los partidos políticos en la España actual. Barcelona: Planeta.

ESCANDELL, Ignasi (2014). El nacionalisme valencià. Els casos del PNPV i la UPV (1978-1983). Afers, 79, 751-770.

FLOR, Vicent (2011). Noves glòries a Espanya. Anticatalanisme i identitat valenciana. Catarroja: Afers.

GASCÓ, Patricia (2010). Els discursos identitaris a la UCD-València (1977-1982). Afers, 67, 641-663.

GILLESPIE, Richard (1991). Historia del Partido Socialista Obrero Español. Madrid: Alianza Universal.

GÓMEZ LLORENTE, Luis (1976). Aproximación a la historia del socialismo español. Madrid: Cuadernos para el diálogo.

JULIÁ, Santos (1997). Los socialistas en la política española, 1879-1982. Madrid Taurus.

MARTÍ, Joan (2017). Socialistes d'un país imaginat. Una història del Partit Socialista del País Valencià (1974-1978). València: Institució Alfons el Magnànim. 
MARTÍN RAMOS, José Luis (1989). Historia del socialismo español, vol. 5. Barcelona: Conjunto Editorial.

MATEOS, Abdón (2007): La Transición del PSOE durante los años setenta. En QUIROSA-CHEYROUZE, Rafael (coord.). Historia de la Transición en España. Los inicios del proceso democratizador (285-299). Madrid: Biblioteca Nueva.

MÍGUEZ, Santiago (1990). La preparación de la transición a la democracia en España. Zaragoza: Universidad de Zaragoza.

MOLINERO, Carme (2011). La oposición al franquismo y la cuestión nacional. En MORENO LUZÓN, Javier. Izquierdas y nacionalismos en la España contemporánea. (235-255). Madrid: Pablo Iglesias.

NOGUERA PUCHOL, José Antonio (1977). Un País Valenciano autónomo en una España democrática. València: Fernando Torres Editor.

NÚÑEZ SEIXAS, Xosé Manoel (2010). Patriotas y demócratas: el discurso nacionalista español después de Franco. Madrid: La Catarata.

PRATS, Lluís Bernat (2010). Nació, Transició i democracia cristiana. La UDPV entre els anys 1974 i 1978. Afers, 67, 619-640.

QUIROGA, Alejandro (2008). Amistades peligrosas. La izquierda y los nacionalismos catalanes y vascos (1975-2008). Historia y Política, 20, 97-127.

QUIROGA, Alejandro (2009). Coyunturas críticas. La izquierda y la idea de España durante la Transición, Historia del presente, 13, 21-40.

RIBERA, Borja (2017). De la unitat a l'enfrontament. Els 9 d'Octubre de 1977, 1978 i 1979, Afers, 88.

RICO, Antoni (2018): La influència del pensament de Joan Fuster en les cultures polítiques dels Països Catalans (1960-1992), Tesis doctoral, Universitat de Girona, 2018.

RODRÍGUEZ-FLORES, Vega (2015). Linici del "pragmatisme autonòmic"? El PSPVPSOE i l'abandó del Consell preautonòmic. Afers, 79, 643-660.

RODRÍGUEZ-FLORES, Vega (2017a). Definir el País Valencià. El Partit comunista i l'autonomia (1971-1977), Afers, 88.

RODRÍGUEZ-FLORES, Vega (2017b): Nación española y Estado Autonómico en el Partido Socialista Obrero Español (1974-1982). Tesis doctoral. Universitat de València.

RUIZ, Manuel (2005). La conquista del Estatuto de Autonomía para Andalucía (19771982). Sevilla: Instituto Andaluz de Administración Pública.

SABIO, Alberto (2015). Las culturas políticas socialista y comunista ante la ruptura pactada: acción colectiva, consenso y desencanto en la transición española, 19751979. En PÉREZ LEDESMA, Manuel; SAZ, Ismael (coords.). Del franquismo a la democracia. 1936-2013, vol. IV (327-360). Madrid: Marcial Pons y Prensas de la Universidad de Zaragoza.

SABIO, Alberto (2017). De la clandestinidad al poder autonómico: La reconstrucción del PSOE en Aragón, 1960-1983. En MATEOS, Abdón; LEÓN Guillermo: La reconstrucción del PSOE durante la Transición. Una perspectiva territorial (13-38). Madrid: UNED. 
SÁNCHEZ, David (2008). De la república federal de las nacionalidades que integran el estado español a la idea de España como nación de naciones: el discurso del PSOE sobre la cuestión nacional entre el congreso de Suresnes y la Constitución de 1978. En NAVAJAS, Carlos; ITURRIAGA, Diego (eds.). Crisis, dictaduras, democracia: I Congreso Internacional de Historia de Nuestro Tiempo (363-373). Logroño: Universidad de la Rioja.

SANZ, Jesús (1982). La cara secreta de la política valenciana. De la predemocràcia al Estatuto de Benicassim. València: Fernando Torres-Editor.

SANZ, Benito (1988). Los socialistas en el País Valenciano (1939-1978). València: Alfons el Magnànim.

SANZ, Benito; FELIP Josep Maria (2006). La construcción política de la Comunitat Valenciana. València: Alfons el Magnànim. 